Documenta \& Instrumenta

ISSN-e: 1697-3798

http://dx.doi.org/10.5209/rev_DOCU.2017.v15.56200

\title{
Cuatro hallazgos aislados de dinares epigráficos latinos hispano- musulmanes en Jaén
}

\author{
Alberto González García ${ }^{1}$; David Martínez Chico ${ }^{2}$
}

Recibido: 30 de enero de 2017 / Aceptado: 10 de mayo de 2017

Resumen. En este trabajo presentamos un estudio histórico-numismático de una serie de monedas halladas de forma aislada en distintas localizaciones de la provincia de Jaén (Andalucía, España). Son cuatro dinares epigráficos latinos del tipo Indicción-Estrella, uno de ellos el de mayor peso hasta ahora conocido de esta tipología.

Palabras clave. Al-Ándalus; conquista islámica; dinares epigráficos latinos.

[en] Four isolated findings of Hispano-Muslim epigraphic Latin dinars in Jaén

Abstract. This paper presents a historical-numismatic study of a series of coins found isolated in several locations of the province of Jaén (Andalusia, Spain). They are four latin epigraphic dinars of the type Indiction-Star, one of which is the heaviest known coin of this typology.

Keywords. Al-Ándalus; Islamic conquest; epigraphic latin dinars.

Sumario. 1. Introducción. 2. Naturaleza de los dinares epigráficos latinos hispano-musulmanes. 3. Contexto histórico de los hallazgos. 4. Conclusiones. 5. Catálogo.

Cómo citar: A. González García y D. Martínez Chico, "Cuatro hallazgos aislados de dinares epigráficos latinos hispano-musulmanes en Jaén”, Documenta \& Instrumenta, 15 (2017), pp. 45-56.

1 Universidad Complutense de Madrid (España)

cuborg1985@gmail.com

2 Universidad de Valencia (España)

david_ele@live.com 


\section{Introducción}

Las monedas que presentamos a continuación, cuatro dinares latinos hispanomusulmanes del tipo Indicción-Estrella ${ }^{3}$, fueron obtenidas a causa de una serie de hallazgos fortuitos a manos de particulares. Aunque no sea el caso, es evidente que deploramos el enorme daño causado por los clandestinos al patrimonio arqueológico, en una búsqueda codiciosa de objetos de valor. No obstante, siempre es preciso documentar el patrimonio histórico independientemente de las circunstancias de su hallazgo, conservación y propiedad. Dadas las circunstancias, nuestra intención no es entrar en la árida problemática de la legalidad de los descubrimientos patrimoniales sin declarar y la retención de las piezas.

Estimamos que, debido a las actuales leyes vigentes en España, no existen alicientes suficientes para obrar de la forma correcta, a resultas de lo cual la mayor parte del material numismático carece de contexto arqueológico, e incluso de la más mínima referencia a su lugar de origen. La necesidad de documentar y publicar estas piezas de turbia procedencia ha sido defendida por innumerables numismáticos españoles de la talla de Felipe Mateu y Llopis (1947) y Leandro Villaronga (1976), sin obviar a los ingleses como Andrew Burnett (1991), de modo que nos consideramos sobradamente justificados para estudiar este tipo de material $^{4}$.

Bajo estas premisas accedimos a estas piezas de indudable escasez en la Península Ibérica, como son los dinares hispano-musulmanes de indicción. Sus hallazgos en ciertos puntos de los valles del Guadalquivir y del Guadalén, en la provincia de Jaén, se pueden vincular con el paso por esta región del emir de Ifriqiya, Musa Ibn Nusayr, acontecido hacia mediados del año 95 de la Hégira (714 de la era cristiana), una vez sometida la mayor parte del antiguo reino visigodo de Toledo, con excepción de la Septimania, aún controlada por el rey Ardón hasta 719.

\section{Naturaleza de los dinares epigráficos latinos hispano-musulmanes}

La significación de las piezas que presentamos viene dada por su relevancia e interés histórico, tratándose de cuatro rarísimos dinares epigráficos latinos de los primeros años de la conquista musulmana del Reino visigodo de Toledo, del tipo Indicción-Estrella, en excelente estado de conservación. Figuran entre los testimonios más tempranos y elocuentes de la conquista musulmana de la Spania visigoda, cuyos hechos son de sobra conocidos (para una reciente revisión, $c f$.

3 Agradecemos a la profesora Almudena Ariza Armada (New York University - Madrid) y a D. David Francés Vañó sus certeros comentarios respecto a la catalogación de las piezas, de complicadísima lectura, cuyas leyendas retrógradas siempre hacen exasperar incluso a los más duchos en la materia. Cualquier error $\mathrm{u}$ omisión en este trabajo debe achacarse a quienes lo firman.

4 Seguimos las mismas líneas metodológicas que en uno de nuestros trabajos previos (Martínez Chico y González García 2017), en el que esa vez nuestra atención se centró en distintos tremisses visigodos (algunos inéditos) y en un curioso nummus de bronce, todos hallados en el norte de Cáceres. 
García Moreno 2013), pero que ha llegado a ser incluso negada por ciertos arabistas, como Olagüe y González Ferrín (cf. García Sanjuán 2013).

Estas emisiones de dinares "transicionales" de los conquistadores musulmanes, con leyendas latinas, fueron acuñadas entre los años 93 y $95 \mathrm{H}$ (octubre de 711septiembre de 714), es decir, en plena conquista de la Península, de ahí su extraordinaria relevancia, y han sido estudiadas en varios trabajos científicos de gran rigor (Walker 1956, xlv-li y 74-75; Navascués 1959; Balaguer 1976a, 27-67 y 87-115, b y c, 1979 y 1988; Pliego 2001; Jonson 2014, 36-37, 86-87, 141-187, 264, $328-332$, 343-346, 390-398, 485-497 y 545-547). Serían seguidas por las primeras emisiones propiamente andalusíes, sólidos, semisses y tremisses con leyendas bilingües árabes y latinas, emitidas al cabo de un hiato de dos años, a partir de $98 \mathrm{H}$, correspondiente a 716-17 (Miles 1950; Balaguer 1976a, 69-115; Jonson 2014, 38, 201-206, 265-266, 332-334, 346-348, 503-505 y 547-548; Ariza 2016).

Las piezas que tratamos presentan en el anverso variantes de la shahada en abreviatura latina como leyenda en la orla (e.g. IN Nomine Dei, Non Deus NiSi Deus SoLuS, Non Similis) y una pequeña estrella de ocho puntas en el centro del campo, mientras que en el reverso figuran los datos de la acuñación, también en la orla (e.g. Novus SoLiDus FeRiTus In SPaNia y la data), y la indicación del año de la indicción (un período fiscal tardorromano de quince años, $c f$. Balaguer 1976a, 39-42; Bagnall-Worp 1978, 12-35; Jonson 2014, 82-84 y 157-182) en el campo. Su escritura retrógrada, el torpe grabado de los caracteres latinos y el hecho de que la mayoría de las veces se indicaran preferentemente las consonantes radicales, con escasas vocales, siguiendo un modelo semita propio de las lenguas árabe y hebrea, evidencia que los monederos fueron muy probablemente árabes o judíos al servicio del emir de Ifriqiya, probablemente procedentes de su capital, Cairuán, donde ya se emitían dinares con caracteres latinos de modelo bizantino (Navascués 1959; Ariza 2015, para el caso idrisí, y 2017; cf. Bar-Magen 2015 sobre unos posibles caracteres judíos en dos piezas).

Los dinares epigráficos latinos hispano-musulmanes están datados entre los años 93H/711-12 y 95H/713-14. No obstante, en algunas de las piezas se ha observado una discordancia entre el año de la Hégira y el de la indicción, hecho que se ha achacado a la negligencia de algunos grabadores de cuños a la hora de la labra (Walker 1956, 73; Balaguer 1976a, 42-47).

Estas monedas de oro, que se comenzaron a acuñar apenas realizado el desembarco de Musa en la Spania visigoda, recordaban a los soldados la autoridad de la que dependían, pero también constituían una declaración de su voluntad de permanencia, un medio en las nuevas relaciones con la población autóctona sometida y una forma de asentar el nuevo orden administrativo y fiscal. Es natural que los soldados y burócratas omeyas, habituados a un sistema monetario derivado de los usos tardorromanos, rechazaran la envilecida moneda visigoda y su extraña metrología. Chalmeta ([1994] 2003, 232-37) señala que los dinares epigráficos tuvieron mucho que ver con la tasación y reparto del valor en numerario de los botines obtenidos, según las partes estipuladas por la normativa islámica.

A nuestro entender, las últimas investigaciones demuestran que las visigodas fueron emisiones relativamente cuantiosas que alimentaban una auténtica economía monetaria en hábitats tanto urbanos como rurales y en distintos niveles sociales, con un comercio más o menos activo, no limitado a las relaciones políticas y 
fiscales de las élites (Marot 2001; Santiago 2011; Doménech 2014, contra Martín Viso 2008 y 2011; Castro Priego 2011 y 2016; Retamero 2011 y Pliego 2011 y 2015). En la práctica, los pactos con los nuevos conquistadores no alteraron, al menos inicialmente, la situación de predominio de las élites terratenientes locales como mediadoras entre sus clientes y el estado central. Conservaron sus bienes y encumbrada posición a cambio del reconocimiento de la nueva autoridad, de la renuncia a sus prerrogativas políticas, y de la recaudación y el pago de los impuestos, lo cual permitió a Tariq y a Musa imponerse a las escasas resistencias presentadas -tras las encarnizadas batallas iniciales- por unas aristocracias fragmentadas que primaban sus intereses personales, destacándose el colaboracionismo de los príncipes witizanos, que conservaron enormes patrimonios fundarios, pero también con los rodriguistas, casando Musa a su hijo 'Abd al-Aziz con Egilona, viuda de Rodrigo ( $c f$. Chalmeta [1994] 2003, 138-42, 149-50, 170-75, 226-29 y 237-41; García Moreno 2013, 290-309, 343-52 y 437-45; García Sanjuán 2013 400-408). Justo a la contra, el creciente autoritarismo político, militar y fiscal del posterior valiato, violentando el status quo preservado por esos primitivos pactos, provocó sucesivas revueltas a partir del quinquenio 102-5H (720-24), empezando por el caso de Pelayo y Asturias (Chalmeta [1994] 2003, 201-213 y 253-305; García Moreno 2013, 493-502).

De igual modo, el thesaurus toledano era uno de los pilares del regnum Gothorum, tanto por su importancia simbólica como por el propio volumen de riqueza acumulada, y apoderarse de él significaba el colapso del Estado (Arce 2011, 83-98). No extraña, pues, que asegurar su control fuera una prioridad mayor para Tariq que la conquista de territorio, y que la resistencia organizada se derrumbara tras su pérdida (Chalmeta [1994] 2003, 153-57; García Moreno 2013, 321-43), con la excepción del usurpador Agila II (710-13), que reinaba en la Tarraconense y Septimania.

La política pactista con las élites locales y la suplantación del sistema políticofiscal de la monarquía visigoda permite apreciar mejor porqué era tan importante la rápida erradicación de la moneda real visigoda y su sustitución por nuevos tipos, además de contribuir a explicar su rápida disolución. La dinámica de regalo, expropiación y nuevo reparto del usufructo del patrimonio estatal entre los partidarios y aliados había sido una constante del reino toledano (Díaz 2012), y Musa adoptó una táctica similar, con gran éxito.

Las crónicas árabes testimonian que el numerario de oro fue retirado inmediatamente de circulación por los conquistadores según llegaban a un nuevo territorio (Conde 1982, 19; cit. por Martín Escudero 2005, 36), produciéndose una "sustitución absoluta del numerario visigodo" (Canto 2011, 135). Y, en efecto, si bien existen muchos y muy cuantiosos tesoros de época visigoda tardía ( $c f$. Miles 1952; Barral i Altet 1976; Vico et al. 2006; Pliego 2009), nunca se han encontrado tesoros en los que coexistan monedas de oro visigodas y andalusíes. La ruptura y la arabización de $102-5 \mathrm{H}$ viene precedida por la emisión de los primeros dinares bilingües, ya propiamente andalusíes e independientes del Magreb, en 98H/716-17, con la llegada del nuevo valí, al-Hurr, a la Península (Balaguer 1976a, 74-75; Bates 1992, 281-82; Ariza 2016, 143-146 y 153-154).

La propia naturaleza física de los nuevos dinares latinos evidenciaba la completa ruptura con los degradados trientes del período terminal del reino 
toledano (cf. Castro Priego 2011; Pliego 2011 y 2015). Para empezar, su iconografía, con una estrella representando quizá el lucero de poniente (Balaguer 1976a, 82-85; Ariza 2001; y 2016, 146-153; Jonson 2014, 147-148), en contraste con los estilizados retratos regios y las cruces características del numerario visigodo. En segundo lugar, su técnica de acuñación también era muy peculiar, siguiendo las prácticas de la ceca de Cairuán, empleando glóbulos en vez de cospeles laminados, lo que resultaba, una vez producida la acuñación, en monedas muy gruesas y de bordes redondeados (Balaguer 1988, 15-16; Pliego 2001, 154). Técnica rudimentaria que, además, manifiesta la fundición de las masas locales de metal precioso, amonedado o no.

El contenido aurífero de estos dinares también es elevado, aunque inferior al de la emisiones norteafricanas muy variable, aproximadamente entre el 60 y el $90 \%$ (Balaguer 1976a, 95-111; Jonson 2014, 328-332), frente al 40-50\% de oro de los tremisses más tardíos, que pesaban poco más de un gramo (Castro Priego 2011; Jonson 2014, 319-320; Pliego 2015). Los análisis de las aleaciones ponen de manifiesto que los dinares epigráficos latinos se produjeron, en efecto, con metal procedente de moneda visigoda (Jonson 2014, 343-345).

Por último, el peso medio de los dinares de indicción que se aproximan al peso teórico tiende a ser levemente superior a los 4,25 g del dinar resultante de la reforma monetaria del califa 'Abd al-Malik (65-86H/685-705), realizada hacia 7779H/696-698, hecho que Bates (1992, 285-89) atribuye a la existencia de un estándar norteafricano que difería del damasceno ( $c f$. Jonson 2014, 273-275). La mayoría de los ejemplares, sin embargo, se encuentran en un amplísimo rango de 3 a casi 5 gramos (Jonson 2014, 279-282). Las cuatro piezas que aquí presentamos pesan, respectivamente, $3,53,3,67,4,45$ y $4,90 \mathrm{~g}$, siendo este último $\left(\mathrm{n}^{\mathrm{o}} 3 \mathrm{del}\right.$ catálogo), con su cospel anormalmente grueso, el dinar epigráfico latino más pesado de todos los conocidos hasta la actualidad, una pieza excepcional comparable sólo a un ejemplar de 4,89 g de la variante $\Lambda \mathrm{I}$ (Jonson 2014, 497).

\section{Contexto histórico de los hallazgos}

Además de las cuatro piezas que presentamos, son escasos los especímenes de dinares latinos hispano-musulmanes cuyo lugar de procedencia exacto es conocido. Contamos en primer con los cuatro dinares astigitanos de 93-94H/711-13 dados a conocer por Ruth Pliego (2001). A ellos se suman el dinar de hallado en Carmona de 93H/711-12 (del tipo SIMILIS), los tres de de 93-95H/711-14 en Córdoba, y una posible pieza de 93H/711-12 en Algeciras (Balaguer 1976b, 28-31), así como la pieza de 94H/712-13 aparecida en Tudején-Sanchoabarca, en las proximidades de Fitero (Medrano 2004). La única gran obra de referencia, la de Anna Balaguer (1976a), carece de un estudio concreto sobre las localizaciones de los hallazgos o la circulación monetaria, debido a la escasa información existente, pero la autora dedicó atención a estos asuntos en un artículo complementario (Balaguer 1976b).

Las cuatro monedas que documentamos aparecieron aisladas en zonas rurales, sin contexto arqueológico, en las poblaciones jienenses de La Carolina, Jabalquinto y Los Villares de Andújar, situadas en la ruta desde Córdoba hasta Despeñaperros, por los valles del Guadalquivir y el Guadalén, el paso natural entre la Depresión 
Bética y la Submeseta Sur. Sus localizaciones concretas pueden apreciarse geográficamente en el subsiguiente mapa de la provincia de Jaén (fig. 1).

Sabemos que, tras asediar Lugo y someter la lejana Gallaecia, Musa fue interceptado por un emisario del califa al-Walid I (86-96H/705-15) y convocado a Damasco. El emir volvió a Toledo, formó un enorme cortejo y marchó siguiendo la antigua vía romana que comunicaba la antigua urbs regia visigoda con el desfiladero de Despeñaperros, desde allí descendió a través de los valles del Guadalén y el Guadalquivir hasta Corduba e Hispalis, y finalmente alcanzó Algeciras, donde se embarcó en du l-hiyya de 95H (agosto-septiembre de 714), rumbo a Tánger (Sánchez-Albornoz 1948; Chalmeta [1994] 2003, 188-92; García Moreno 2013, 426-37, niega la historicidad de estas campañas en el noroeste peninsular, a nuestro entender erróneamente).

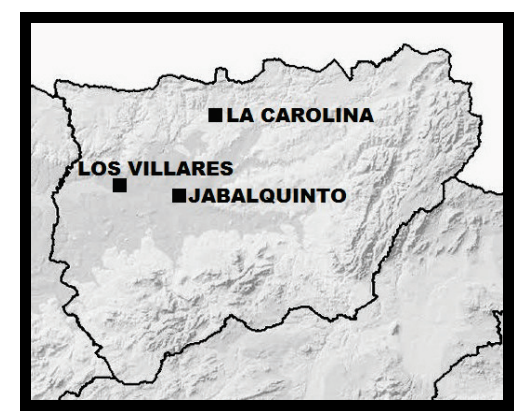

Figura 1. Mapa de la provincia de Jaén con las localidades de origen de las monedas.

Si las piezas que aquí presentamos parecen tener una más que probable relación con el paso de las huestes de Musa, el trayecto por el valle del Guadalquivir y hasta el Estrecho de Gibraltar podría permitir vincular esta concentración de botín y tropas con las piezas sueltas localizadas en Córdoba, Carmona y Algeciras (Balaguer 1976b, 28-31), así como con el tesorillo de cuatro dinares similares hallado en Écija (Pliego 2001), con idéntica datación a nuestras piezas (9394H/711-713). De igual modo, el dinar de Tudején-Sanchoabarca puede relacionarse con el paso de Musa por la ribera del Ebro hasta Vareia, girando hacia Pamplona, donde recibió la sumisión del conde Casio, fundador epónimo de los Banu Qasi (Chalmeta [1994] 2003, 186-88). La presencia de este dinar en la actual Navarra permite, hasta cierto punto, rechazar la teoría de García Moreno (2013, 442-45), quien estima improbable que Musa alcanzara Pamplona o llegara a otorgar la capitulación a Casio. También cabe señalar la existencia de precintos de plomo que sellaban las sacas de botín de Musa, hallados por ejemplo en Sidonia y Sevilla, e ignorados hasta fechas muy recientes, pero de capital importancia (Ibrahim 2011). Como vemos, todos estos hallazgos se encuentran justo en la ruta seguida por las huestes de Musa, de modo que la tendencia parece evidente.

Esta movilidad de los ejércitos musulmanes durante los primeros años de la conquista nos permite entrar a valorar la cuestión de la ceca. Tradicionalmente se ha sostenido que los dinares de indicción fueron acuñados en Corduba, nueva "capital" peninsular, en Hispalis, primera gran ciudad tomada por Musa, o en 
Toledo, la antigua capital goda ( $c f$. Walker 1956, l; Navascués 1959, 45-48; Balaguer 1976a, 87-93). Sin embargo, a nuestro juicio esta es una apreciación errónea. Las similitudes con las emisiones norteafricanas de la época, el gran número y diversidad de cuños, unidos a la escasa calidad de la factura, la aleación irregular y variable de muchas piezas, la imposibilidad logística de mantener un suministro regular desde una ceca urbana fija hasta un ejército conquistador en marcha por un país que está siendo ocupado, a pesar de la escasa resistencia, y el hecho de que la capitalidad aún se encontraba de facto donde estuviera el emir Musa, nos hace pensar en una ceca volante que acompañaba a su ejército y producía de forma irregular para abastecer a la tropa y a las nuevas áreas conquistadas, dependiendo de las variables cantidades de metal disponible como resultado de los botines y tributos obtenidos, algo ya propuesto por Balaguer (1976a, 92-93), Bates (1992, 276-77), Canto e Ibrahim (2004, 38 y 65), el propio Canto $(2011,136)$, García Moreno $(2013,469)$ o Jonson $(2015$, 86-87 y 159, que habla de una ceca principal y varias secundarias), contra lo postulado por Chalmeta ( [1994] 2003, 190), que apuesta por Toledo, o Pliego (2001, 150 y 154), que sigue defendiendo el origen hispalense. De hecho, las emisiones de estas piezas coinciden exactamente con la presencia en Spania de Musa, responsable asimismo de las primeras monedas islámicas en el Norte de África, región donde se reanuda la acuñación al volver el emir en $95 \mathrm{H}$, camino de Siria, tras un hiato de varios años, que coincide exactamente con sus campañas en la Península Ibérica (Balaguer 1976a, 47-50; Bates 1992, 276). Todo ello refuerza el argumento de la existencia de un taller móvil que acompañó al emir en Spania, y probablemente permaneciera más tiempo en Mérida, durante los catorce meses de asedio hasta su rendición (Chalmeta [1994] 2003, 131, 172-176 y 206; Alba Calzado-Mateos Cruz 2011; García Moreno 2013, 392-399), y en Toledo, donde Musa tomó posesión del tesoro visigodo en el verano de $94 \mathrm{H} / 712-13$, y donde reorganizó su séquito y equipaje antes de partir hacia Siria en 95H/713-14 (Chalmeta [1994] 2003, 177-78 y 190-1; García Moreno 2013, 424-26 y 458-67, habla de una rápida partida en 713, dentro de su equívoca reconstrucción de las campañas de Musa). Parece descartable atribuir total o parcialmente estas emisiones a Tariq, un subordinado sin autoridad suficiente, reprendido y maltratado por el emir por su excesiva iniciativa en la conquista del reino toledano.

Por último, las condiciones de los hallazgos, tratándose de piezas aisladas y situadas a poca profundidad, en terrenos agrícolas, nos indican que su pérdida fue probablemente involuntaria, y no el resultado de ocultaciones intencionadas. Este argumento se ve reforzado por el apresuramiento propio de los ejércitos en marcha, y concretamente el de Musa, que partía cargado de riquezas para no volver. Llamado a comparecer con urgencia ante la autoridad califal en Damasco, como hemos indicado, el emir de Ifriqiya llegó a la capital omeya en gumada I de $96 \mathrm{H}$ (enero de 715), tras atravesar el Magreb, Egipto y Palestina con su fabuloso botín de metales preciosos, joyas y cautivos. Sin embargo, fue recibido con hostilidad, destituido y condenado (junto con sus familiares y clientes) a pagar una cuantiosísima multa, 4.030.000 dinares "de peso [legal] y buena [ley]", por apropiación indebida, y murió asesinado poco después por encargo del nuevo califa, Suleimán (96-99H/715-17), temeroso del inmenso poder adquirido por el 
prócer yemení en sus enormes dominios de Occidente (Chalmeta [1994] 2003, 192201; García Moreno 2013, 467-75).

Podemos considerar los detalles de esa multa indicativos de la cuantía del thesaurus godo, así como del destino de la mayor parte de las primeras acuñaciones musulmanas de oro en Spania: parece lógico suponer que el grueso de las nuevas piezas acompañó al emir Musa hasta Damasco, donde sería confiscado por el gobierno omeya, que poco después emprendería un nuevo, costoso y fallido intento de conquistar Constantinopla (99-100H/717-18). La propia circunstancia del viaje con el botín visigodo, y la indicación específica sobre el peso y la ley apunta con fuerza a que los dinares en cuestión no eran los habituales procedentes de la ceca califal.

\section{Conclusiones}

Los cuatro dinares de Indicción-Estrella que aquí presentamos, resultado de pérdidas fortuitas y localizados en contextos rurales de la Provincia de Jaén, son de gran interés para el estudio de la conquista musulmana del reino visigodo, pudiendo vincularse con la retirada, a través de esa región, del emir Musa de la Península, cargado de botín, tras sus campañas de conquista, en 95H/713-14. Con 4,90 g, uno de ellos el de mayor peso hasta ahora conocido de esta tipología. Se trata de piezas acuñadas casi con seguridad en una ceca móvil que acompañó al emir de Ifriqiya en Spania, fundiendo y acuñando los botines obtenidos, en especial los tremisses visigodos. Dan testimonio de la sustitución del numerario de oro, uno de los símbolos más visibles de la monarquía toledana, y la suplantación de su sistema político-fiscal, permitiendo la rápida acomodación de las élites locales en el seno del nuevo dominio musulmán, dentro de la política de pactos característica de la conquista, si bien cabe recordar que no estuvo -ni mucho menos- exenta de violencia y resistencias.

\section{Catálogo}

Pieza 1 (procedente de La Carolina o aledaños).

Anv: IN N D N D NS D SLS N S alrededor de estrella de 8 puntas (IN Nomine Dei Non Deus NiSi Deus SoLuS Non Similis; "En el nombre de Dios, No [hay] Dios sino Dios, sólo, no [tiene] semejante").

Rev: N SLD FRT IN SPN ANN XCIIII alrededor, y en parte central, INDC XI (Novus SoLiDus FeRiTus In SPaNia ANNo XCIIII - INDiCción XI; "Nuevo sólido hecho en Hispania año 94 - Indicción XI" = año 94H = 712-13).

Datos: 3,53 g / $13 \mathrm{~mm}$. Observaciones: Reverso empastado.

Pieza 2 (hallada en la zona de influencia de Isturgi, Los Villares de Andújar, a unos tres kilómetros río arriba, en el mismo margen del Gualdaquivir donde se sitúa la ciudad). 
Anv: ¿IN N D N D NS D SLS N S? alrededor de estrella de 8 puntas (IN Nomine Dei Non Deus NiSi Deus SoLuS Non Similis; "En el nombre de Dios, No [hay] Dios sino Dios, sólo, no [tiene] semejante").

Rev: N SLD FRT IN SPN ANN XCIIII alrededor, y en parte central, INDC X (Novus SoLiDus FeRiTus In SPaNia ANNo XCIIII; "Nuevo sólido hecho en Hispania año 93 - Indicción X" = año $93 \mathrm{H}=711-712$ ).

Datos: 3,67 g / 10-14 mm. Observaciones: incisión superficial en el reverso con forma de $\mathrm{X}$ o aspa, para comprobar su autenticidad o que no fuera forrada.

Pieza 3 (hallada frente a Isturgi, Los Villares de Andújar, en la orilla opuesta del río, más concretamente donde se supone que estaba el muelle de embarcación de la ciudad).

Anv: ¿IN N D N D NS D SLS N S? alrededor de estrella de 8 puntas (IN Nomine Dei Non Deus NiSi Deus SoLuS Non Similis; "En el nombre de Dios, No [hay] Dios sino Dios, sólo, no [tiene] semejante").

Rev: N SLD FRT IN SPN ANN XCIIII alrededor, y en parte central, INDC XII (Novus SoLiDus FeRiTus In SPaNia ANNo XCIV - INDiCción XII; "Nuevo sólido hecho en Hispania año 94 - Indicción XII" = año 94H = 712-713).

Datos: 4,90 g / $11 \mathrm{~mm}$. Observaciones: Cospel grueso.

Pieza 4 (procedente de Jabalquinto).

Anv: IN N D N D NS D SLS N S alrededor de estrella de 8 puntas.

IN Nomine Dei Non Deus NiSi Deus SoLuS Non Similis

("En el nombre de Dios, No [hay] Dios sino Dios, sólo, no [tiene] semejante").

Rev: N SLD FRT IN SPN ANN XCIII alrededor, y en parte central, INDC XI (Novus SoLiDus FeRiTus In SPaNia ANNo XCIII - INDiCción XI; "Nuevo sólido hecho en Hispania año 93 - Indicción XI" = año 93H = 711-12).

Datos: 4,45 g / $12 \mathrm{~mm}$.
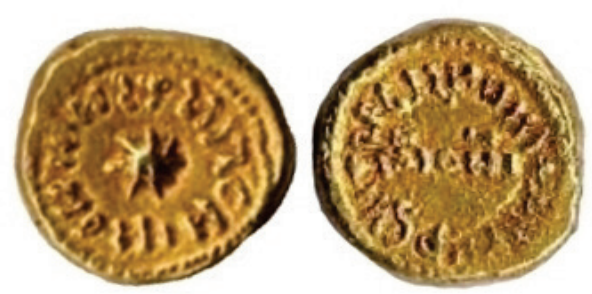

1
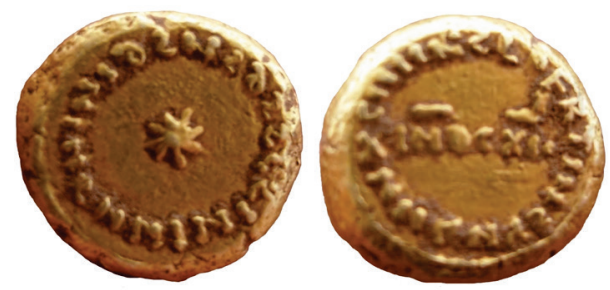

3
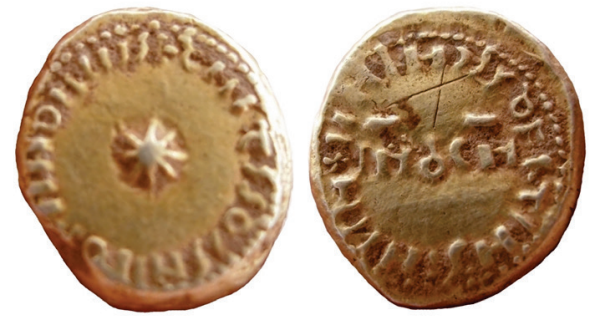

2
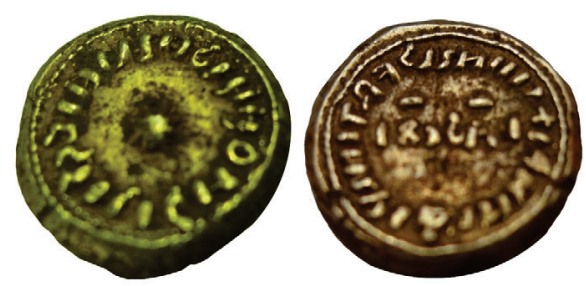

4

Figura 2. X 2 . 


\section{Bibliografía}

Alba Calzado, M. y Mateos Cruz, P. (2011): "El paisaje urbano de Mérida en torno al año 711”, en Zona arqueológica 15-1. Ejemplar dedicado a: 711, arqueología e historia entre dos mundos, pp. 25-36.

Arce, J. (2011): Esperando a los árabes: Los visigodos en Hispania (507-711), Madrid.

Ariza Armada, A. (2001): "Aniconismo e iconografía monetal en al-Andalus", en A. Janzon (ed.), Primer Simposio España y Estados Unidos. Una mirada desde el Instituto. Internacional, Madrid, pp. 23-33.

Ariza Armada, A. (2015): "Signos y Símbolos judíos en la moneda islámica occidental (siglos II-III/VIII-IX). El caso Idrisí", Anaquel de Estudios Árabes 26, pp. 29-54.

Ariza Armada, A. (2016): "Los dinares bilingües de al-Andalus y el Magreb", Revista Numismática Hécate 3, pp. 137-158.

Ariza Armada, A. (2017): "Símbolos judíos en la moneda omeya", en preparación.

Bagnall, R.S. y Worp, K.A. (1978): The Chronological Systems of Byzantine Egypt, Leiden.

Balaguer Prunes, A. M. (1976a): Las emisiones transicionales árabe-musulmanas de Hispania, Barcelona.

Balaguer Prunes, A. M. (1976b): "Nuevos datos sobre la moneda transicional árabe-musulmana de Hispania y África", Gaceta Numismática 42, pp. 27-41.

Balaguer Prunes, A. M. (1976c): "Descripción y comentario de doce monedas transicionales acuñadas en el norte de África e Hispania", Gaceta Numismática 43, pp. 32-51.

Balaguer Prunes, A. M. y Bates, M. L. (1979): "Early Islamic Transitional Gold Issues of North Africa and Spain", American Numismatic Society. Museum Notes 24, pp. 225-241.

Balaguer Prunes, A. M. (1988): "Las emisiones transicionales árabe-musulmanas de Al-Andalus. Nueva síntesis", en I Jarique de Estudios Numismáticos Hispano-Árabes, Zaragoza, pp. 11-28.

Bar-Magen Numhauser, A. (2015): "Una supuesta moneda del siglo VIII con 'caracteres hebreos' - Nuevos datos", OMNI 9, pp. 196-211.

Barral i Altet, X. (1976): La circulation des monnaies Sueèves et Visigothiques. Contribution à l'historire économique du royaume visigot. Beihefte der Francia, vol. 4, Múnich.

Bates, M.L. (1992): "The Coinage of Spain Under the Umayyad Caliphs of the East, 711-750", en III Jarique de numismática hispano-árabe [Madrid, 13-16 diciembre 1990], Madrid, pp. 271-289.

Burnett, A. (1991): Coins. Interpreting the Past, Londres.

Campos López, M.T. (2001): "Feluses en las excavaciones de Jaén”, en IV Jarique de Numismática Andalusí, Jaén, pp. 111-120.

Canto García, A. (2011): "Las monedas y la conquista", Zona arqueológica 15-1. Ejemplar dedicado a: 711, arqueología e historia entre dos mundos, pp. 135146.

Canto García, A. e Ibrahim, T. I. H. (2004): Moneda andalusí. La colección del Museo Casa de la Moneda, Madrid. 
Castro Priego, M. (2011): "La circulación monetaria de los siglos VII-VIII en la Península Ibérica: un modelo en crisis", en E. Baquedano (ed.), 711. Arqueología e historia entre dos mundos (Zona Arqueológica 15), Madrid, pp. 223-242.

Castro Priego, M. (2016): "Absent Coinage: Archaeological Contexts and Tremisses on the Central Iberian Peninsula in the 7th and 8th Centuries AD", Medieval Archaeology 60-1, pp. 27-56.

Chalmeta Gendrón, P. ([1994] 2003): Invasión e islamización. La sumisión de Hispania y la formación de Al-Andalus, Jaén.

Conde, J.A. (1982): Memoria sobre la moneda arábiga y en especial sobre la acuñada en España, por los príncipes musulmanes leída en la Real Academia de la Historia en junta del 21 de julio de 1804, Madrid.

Díaz, P.C: (2012): "Confiscations in the Visigothic reign of Toledo. A political instrument", en P. Porena e Y. Rivière (eds.), Expropiations et consfiscations dans les royaumes barbares. Une approche regionales (Collection de l'Écola Française de Rome 470), Roma, pp. 93-112.

Doménech Belda, C. (2014): "Moneda y espacios de poder en el reino visigodo. Los tremises de El Tolmo de Minateda (Hellín, Albacete)", Arqueología y Territorio Medieval 21, pp. 9-37.

García Moreno, L. A. (2013): España 702-719: la conquista musulmana, Sevilla.

García Sanjuán, A. (2013): La conquista islámica de la península Ibérica y la tergiversación del pasado, Madrid.

Ibrahim, T. I. H. (2011): "Nuevos documentos sobre la Conquista Omeya de Hispania: los precintos de plomo", Zona arqueológica 15-1. Ejemplar dedicado a: 711, arqueología e historia entre dos mundos, pp. 147-161.

Jonson, T. (2014): A Numismatic History of the Early Islamic Precious Metal Coinage of North Africa and the Iberian Peninsula, Oxford.

Marot, T. (2001): "La Península Ibérica en los siglos V-VI: consideraciones sobre provisión, circulación y usos monetarios", Pyrenae 31-32, pp. 133-160.

Martínez Chico, D. y González García, A. (2017): "Nuevos hallazgos monetales visigodos. Oro y bronce en el norte de Cáceres", Habis 48. En prensa.

Martín Escudero, F. (2005): El tesoro de Baena: reflexiones sobre circulación monetaria en época omeya, Madrid.

Martín Viso, I. (2008): "Tremisses y potentes en el nordeste de Lusitania (siglos VI-VII)", Mélanges de la Casa de Velázquez 38-1, pp. 175-200.

Martín Viso, I. (2011): "Circuits of Power in a Fragmented Space: gold coinage in the Meseta del Duero (Sixth-Seventh Centuries)", en J. Escalona y A. Reynolds (eds.), Scale and Scale Change in the Early Medieval Ages: Exploring Landscape, Local Society, and the World Beyond, Londres, pp. 215-252.

Mateu y Llopis, F. (1947): "Hallazgos numismáticos musulmanes", Al-Andalus : revista de las Escuelas de Estudios Árabes de Madrid y Granada 12-2, pp. 481483.

Medrano Marqués, M. (2004): "El yacimiento visigodo y musulmán de TudejénSanchoabarca", Trabajos de Arqueología Navarra 18, pp. 65-90.

Miles, G. C. (1950): The Coinage of The Umayyads of Spain, Nueva York.

Miles G. C. (1952): The Coinage of the Visigoths of Spain. Leovigild to Achila II, Nueva York. 
Navascués, J. M. de (1959): “Los sueldos hispano-árabes. Catálogo de las primitivas monedas arábigo-españolas que se guardan en el Museo Arqueológico Nacional y en el Instituto de Valencia de Don Juan en Madrid", Numario hispánico 8, pp. 5-66.

Pliego Vázquez, R. (2001): "El dinar epigráfico latino acuñado en al-Andalus: una reinterpretación a la luz de nuevos hallazgos", Numisma 254, pp. 139-154.

Pliego Vázquez, R. (2009): La moneda visigoda, Sevilla.

Pliego Vázquez, R. (2011): "La moneda en el ocaso del reino godo de Hispania", Zona arqueológica 15-2. Ejemplar dedicado a: 711, arqueología e historia entre dos mundos, pp. 323-337.

Pliego Vázquez, R. (2015): "El tremis de los últimos años del Reino Visigodo (702-714)", en P. Sénac y S. Gasc (eds.), Monnaies du haut Moyen Âge: histoire et archéologie (péninsule Ibérique - Maghreb, VIIe-XIe siècle), Toulouse, pp. 17-58.

Retamero, F. (2011): "La moneda del Regnum Gothorum (ca. 575-714): Una revisión del registro numismático", en P. C. Díaz e I. Martín Viso (eds.), Between Taxation and Rent. Fiscal problems from Late Antiquity to Early Middle Ages. Entre el Impuesto y la Renta. Problemas de la fiscalidad tardoantigua y altomedieval, Bari, pp. 189-220.

Salvatierra Cuenca, V., Serrano Peña, J. L. y Cano Carrillo, J. (2001): “El Jaén islámico. La moneda en la identificación de las primeras fases de la ciudad", en IV Jarique de Numismática Andalusí, Jaén, pp. 95-109.

Sánchez-Albornoz, C. (1948): "Itinerario de la conquista de España por los musulmanes", Cuadernos de Historia de España 10, pp. 21-74.

Santiago Fernández, J. de (2011): "Legislación y moneda en la Hispania visigoda", Mélanges de la Casa de Velázquez. Nouvelle série 41-2, pp. 55-74.

Vico, J., Cores, M. C. y Cores, G. (2006): Corpus Nummorum Visigothorum, Ca 575-714. Leovigildus-Achila, Madrid.

Villaronga, L. (1976): "Comentarios sobre metodología en la investigación numismática", Numisma 138-143, pp. 17-37.

Walker, J. A. (1956): The Muhammadan Coins in the British Museum. II: A Catalogue of the Arab-Byzantine and Post-Reform Umayyad Coins, Londres. 